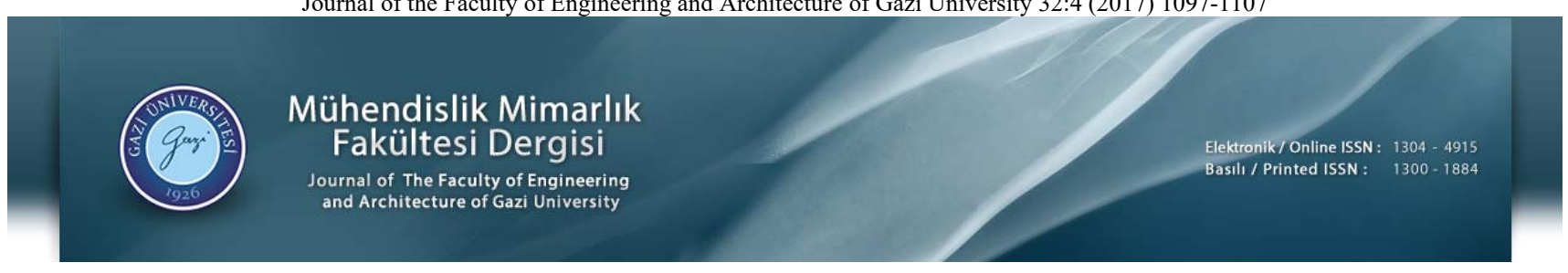

\title{
Değiştirilmiş ateşböceği optimizasyon algoritması ile kural tabanlı çoklu sınıflama yapılmas1
}

İbrahim Berkan Aydilek (iD*

Harran Üniversitesi, Mühendislik Fakültesi, Bilgisayar Mühendisliği Bölümü, Osmanbey Kampüsü, 63300, Şanlıurfa, Türkiye

Ö N E Ç I K A N L A R

- Sinıflama kuralı keşfi için esnek uygunluk fonksiyonu

- Güçlü kurallar için geliştirilebilir birey yapısı

- İyileştirilmiş ateşböceği algoritması

Makale Bilgileri

Geliș: 16.06.2016

Kabul: 10.08.2017

DOI:

$10.17341 /$ gazimmfd.369406

Anahtar Kelimeler:

Ateşböceği optimizasyon algoritmas1,

kural çıkarımı,

kural tabanlı siniflama

\section{ÖZET}

Son yıllarda doğadan esinlenerek oluşturulmuş modern sürü zekalı optimizasyon algoritmaları daha popüler hale gelmiştir. $\mathrm{Bu}$ optimizasyon tekniklerinden biri de ateşböceği algoritmasıdır. Ateşböceği algoritması doğadaki ateşböceklerinin yaydıkları 1şık şiddetine göre daha az parlak olanın parlak olana doğru yönelme prensibini temel alarak çalışır. Doğada 1şık, gideceği mesafe ve bulunduğu ortam türüne göre belirli bir miktar emilime uğradığından dolayı şiddeti azalarak yayılmaktadır. Bu yüzden, bu makalede ortamda yani havada meydana gelen anlık değişimlerin ateşböceği algoritması tarafından dikkate alınması önerilmiş ve böylece algoritmanın daha iyi olması sağlanmıştır. Bu şekilde elde edilen değiştirilmiş ve iyileştirilmiş ateşböceği algoritması, literatür çalışmalarında sıklıkla kullanılan çok sınıflı özelliğe sahip iris, car, zoo gibi üç veri kümesi üzerinde sınıflama amacıyla uygulanmıştır. Kural tabanlı sınıflama yapabilmek için her sınıf etiketine ait kural elde edilerek kural listesi oluşturulmuş ve sınıflama başarısı C4.5, PART, Naive-Bayes gibi bilinen diğer sınıflama yöntemleri ile karşılaştırılmıştır. Elde edilen deneysel sonuçlarda, önerilen sınıflama yönteminin oldukça yeterli ve başarılı sonuçlar verdiği görülmüsşür.

\section{Multi-class classification with modified firefly optimization algorithm}

\section{H I G H L I G H T S}

- $\quad$ Flexible fitness function for discovering classification rules

- Improvable individual structure for robust rules

- Improved firefly algorithm

\section{Article Info}

Received: 16.06 .2016

Accepted: 10.08 .2017

DOI:

10.17341/gazimmfd.369406

Keywords:

Firefly optimization algorithm,

rule extraction, rule based classification

\section{ABSTRACT}

In recent years, nature inspired, modern swarm intelligence optimization algorithms have become more popular. One of these optimization techniques is firefly algorithm. Firefly algorithm works based on the principle in the nature, according to its light spreading, the less bright fireflies are directed towards the brighter one. In the nature, intensity of light decreases during spreading, due to suffering a certain amount of absorption according to environment kind and distance to go. Therefore, in this paper we presented a modified firefly algorithm which takes into account changings of the environment situations. Proposed method makes improvement on standard firefly algorithm and is applied for classification on iris, car and zoo multi-class datasets which are frequently used in literature. Classification rules are obtained corresponding to each class label and rule-based classification is done. Classification accuracy is compared with other known classification methods C4.5, PART and Naive-Bayes. The obtained experimental test results are showed that proposed classification method has quite adequate and successful results. 


\section{GÍRIŞ (INTRODUCTION)}

Optimizasyon birçok alternatif içerisinden en uygun ve iyiyi bulmak olarak tanımlanmaktadır. Kablosuz ağlar [1] ve çizelgeleme [2] gibi çok farklı problemlerde başarılı bir şekilde kullanılmaktadır. Bugüne kadar doğadan esinlenerek oluşturulmuş ve değiştirilmiş yapay arı kolonisi [3], bakteriyel besin arama [4] gibi çok sayıda optimizasyon algoritması mevcuttur. Bunların içinde en fazla bilinenler olarak: genetik algoritma, yapay arı kolonisi ve parçacık sürü algoritmaları sayılabilir. Bu optimizasyon algoritmalarının bazı eksiklikleri ve zayıf yönlerine karşı daha modern algoritmalar ve iyileştirmeler gün geçtikçe artarak geliştirilmeye devam etmektedir [5]. $\mathrm{Bu}$ modern algoritmalardan biri de ateşböceği optimizasyon algoritmasıdır. Ateşböceği algoritması, parçacık sürü algoritmasının tüm parçacıkların en iyiye yönelmesini daha ağırlıklı ve sınırlı yapılabilmesi için geliştirilmiş sürü zekalı bir algoritmadır. Doğadaki ateşböcekleri kimyasal olarak ürettikleri soğuk 1şık kabiliyetleri ile çiftleşme, haberleşme ve avlanma gibi faaliyetleri yerine getirmektedirler. $\mathrm{Bu}$ şekilde, parlak 1şık şiddetine sahip ateşböceği diğer daha az parlak olan ateşböceğini cezbederek kendisine doğru çekmektedir [6]. Işık şiddeti optimizasyon algoritmasının uygunluk (amaç) fonksiyonu olarak kullanıldığında daha az parlak olanın parlak olana yönelmesi uygun veya en iyiyi bulma sonucunu doğurmaktadır [7]. Işık, hava gibi bir ortamda yayılırken emilime uğramakta ve yayıldıkça şiddeti azalmaktadır. Hava gibi durumu değişkenlik (sisli, bulutlu gibi) gösteren bir ortam için kullanılan algoritmanın 1 şık soğurma parametre değeri de değişkenlik göstermelidir. Bu makalede, rastgele değişkenlik gösteren 1ş1k soğurma değerine sahip bir yaklaşım önerilmiştir. Önerilen bu yaklaşım ile değiştirilmiş ve daha iyileştirilmiş bir ateşböceği algoritması elde edilmiştir.

Veri kümeleri, yapısı itibarı ile içerisinde veri kayıtları ihtiva eden bir yapıdadır [8]. Veriden değerli bilgi etmenin bir yolu kural çıkarımı ile gerçekleşmektedir. Veriden elde edilen bu kurallar, uzman sistemler gibi kural tabanlı sistemlerde kullanılabileceği gibi bilinmeyen bir veri kümesi örneğini sınıflama amacıyla da kullanılabilir. Sınıflama işlemi, bilinen, sınıflara ayrılmış veri kayıtları ile oluşturulmuş bir modelin, daha sonra bilinmeyen bir örneği sınıflaması olarak tanımlanabilir. Böylece sınıf etiketi bilinmeyen bir örneğe ait sınıf etiket değeri tahmin edilebilmektedir. Veri kümelerindeki kayıtlar birden fazla özellik ve her özelliğin farklı sayıda değer alabildiği bir yapıda olabilmektedir. Bu yapıdaki veri kümelerindeki bir sınıfi en iyi tanımlayan, kapsayan kuralın bulunması klasik bir optimizasyon problemine dönüşebilmektedir. Sezgisel optimizasyon algoritmaları her zaman en doğru sonucu vermeyi garanti etmemek ile birlikte, algoritmanın çalışması sonlanınca çözüm için bir öneride bulunarak en iyiyi, uygunu bulmayı amaçlar. Bahsedilen bu şekilde ve amaçla kullanıldığında ateşböceği optimizasyon algoritması veri kümesinden bilgi ve kural çıkarımı yapabilmekte ve sınıflama amacıyla kullanılabilmektedir. $\mathrm{Bu}$ makalenin sonraki ikinci bölümünde literatür özeti ve konu ile ilgili diğer çalışmalardan bahsedilmiştir. Üçüncü bölümde ateşböceği optimizasyon algoritması detaylı açıklanmış ve dördüncü bölümde algoritma üzerinde önerilen değişiklik anlatılarak, optimizasyon kıyaslama fonksiyonları üzerinden karşılaştırılmalar yapılmıştır. Beşinci bölümde ise önerilen çoklu sınıflama yapan kural tabanlı sınıflayıcı yaklaşım açıklanmış ve altıncı bölümde deney sonuçları ve tartışmalar yapılarak en son yedinci bölümde de elde edilen genel sonuçlar verilmiştir.

\section{LITERATÜR ÖZETİ VE İLGILİ ÇLISYMALAR (LITERATURE REVIEW AND RELATED WORKS)}

Rudzinski [9], bulanık kural tabanlı bir sinıflandırıcı oluşturabilmek çok amaçlı genetik algoritma kullandı. Bu çalışmada, bulanık kümelerden elde edilen kurallar, genetik algoritma ile optimize edilerek kural kümeleri elde edildi. Böylece genetik algoritmada kullanılan kromozom yapısıyla başarılı bir sınıflayıcı yapılabildiği gösterilmiştir. Wu vd. [10] değiştirilmiş karınca optimizasyon algoritması ile bulanık bir sınıflayıcı metot geliştirdiler. Bu çalışmada modern karınca optimizasyon tekniği ile kural çıkarımı ve sınıflama yapılabildiği gösterilmiştir. Fakat başlangıç kurallarının oluşturulma sürecinde ön işleme yapılması, yaklaşımın karmaşık ve daha uzun çalışma süresine ihtiyaç duymasına sebebiyet verebilmektedir.

Lee vd. [11] web sayfalarını sınıflamak için parçacık sürü ve genetik algoritmaları temel alan yeni bir sürü optimizasyon algoritması önerdiler. Kromozom yapısının içine web sayfasına ait başlık, gövde gibi bölüm metinlerini ikili sayı olarak kodlayarak önceden belirlenmiş başlıklara olan (sanat, bilgisayar, sağlık, bilim vb.) benzerliğini göre sınıflama yaptılar. Pourpanah vd. [12] sinıflama ve kural çıkarımı yapabilmek için yeni bir hibrit yöntem geliştirdiler. Bulanık ARTMAP ve Q-öğrenme yöntemleri ile veri kümesi daha iyi öğrenilerek genetik algoritma ile özellik seçimi ve kural çıkarımı yaptılar. Özellik seçimi ile verinin kompleks yapısı azaltılarak kural çıkarımı daha da kolaylaştırıldı. Elde edilen sonuçlar yeni hibrit yöntemin başarılı olduğunu gösterdi.

Wang vd. [13] ateşböceği algoritmasında kullanılan sabit parametreleri, böcekler arasındaki mesafeye göre değiştiren bir öneride bulundular. Yapılan bu çalışmada böcekler arasındaki mesafeye göre, 1şık soğurma katsayısı ve başlangıç çekicilik parametre değerleri hesaplanmıştır [14]. Bu çalışmalarda, ilgili parametre değerlerinin dinamik olarak değiştirilmesi sonucunda ateşböceği optimizasyon algoritmasında başarılı sonuçlar elde edildiği gösterilmiştir. Genellikle kural çıkarımı yapılan genetik algoritma ile ilgili önceki çalışmalarda kromozom yapısı tek bir kural veya kural listesi şeklinde oluşturulmuş ve böylece başarılı sınıflamalar yapıldığı görülmüştür. Bu çalışmaların bazıları şu şekildedir: veri madenciliğinde genetik algoritma ile sınıflama kuralı keşfi [15], genetik algoritma ile daha anlaşılır sınıflama kuralları keşfi [16], rastgele yapıda 
olmayan başlangıç popülasyonuna sahip genetik algoritma ile sinıflama kuralı madenciliği [17], genetik algoritma kullanarak örüntü sinıflama [18], dağıtık genetik algoritma kullanarak sınıflama kuralı keşfi [19], genetik algoritma kullanarak sınıflama kuralları oluşturmak için bilgi elde etme aracı [20], veri madenciliğinde kural keşfi için genetik algoritma [21], büyük veri kümelerinde sınıflama kuralı madenciliği için zeki bir genetik algoritma [22], genetik programlama kullanarak çoklu anlaşılır sınıflama kuralı madenciliği [23]. Fakat ateşböceği algoritmasının genetik algoritmaya göre daha yeni ve daha basit uygulanabilir olması ayrıca bazı optimizasyon problemlerinde daha iyi sonuçlar elde edildiğinin [24] gösterilmesi üzerine kural çıkarım süreci bu çalışmada iyileştirilmiş ateşböceği algoritması ile yapılmıştır. Hibrit bulanık ateşböceği yaklaşımı ile kural tabanlı sınıflama çalışması [25], bulanık prensipler ve kural ön işleme süreçlerinin olması gibi sebeplerle karmaşık ve çalışma süresinin fazla olması yönünden çalışmamıza göre dezavantajlı durumda olmaktadır.

$\mathrm{Bu}$ çalışmada, rastgele 1şık soğurma katsayı değeri ile önerilen değiştirilmiş ateşböceği algoritmasının kullanılması, standart ateşböceği algoritmasının kullanılmasına göre üstünlükler sağladığı gösterilmektedir.

\section{ATEŞBÖCEĞİ OPTIMMIZZASYON ALGORITTMASI (FIREFLY OPTIMIZATION ALGORITHM)}

Doğadan esinlenerek oluşturulmuş meta-sezgisel optimizasyon algoritmaları, optimizasyon çalışmalarında son yıllarda daha başarılı ve popüler hale gelmiştir. Ateşböcekleri, doğada yaklaşık iki bin türü bulunan sıcak ve tropik bölgelerde yaşayan bir böcek türüdür. Ateşböcekleri kimyasal olarak soğuk 1şı oluşturabilme kabiliyetleri sayesinde karşı cinsi etkileyerek üreme, avlanma ve düşmanlarından korunma gibi eylemleri yerine getirmektedir. Ateşböceği optimizasyon algoritması eniyileme yapan sürü zekalı yaklaşımlardan biridir [25]. Bu algoritma, doğadaki ateşböceklerinin çekiciliğine bağlı olarak birbirlerine veya rastgele bir yöne doğru hareket etme prensibini temel alarak çalışmaktadır [26]. Ateşböceği algoritmasını daha kolay ve anlaşı1ır oluşturabilmek için üç adet varsayım kural kabul edilmektedir [27].

- Tüm ateşböcekleri cinsiyetsiz kabul edilir. Böylece tüm ateşböcekleri geri kalan diğer ateşböceklerini etkileyebilir.

- Çekicilik ateşböceğinin parlaklığı ile ilgilidir. Bu şekilde, iki adet 1şık yayan ateşböceğinden daha sönük 1şığa sahip olan parlak olana doğru hareket eder. Parlaklık aradaki uzaklığa bağlı olarak değişir. Eğer parlaklık seviyesi eşit ise rastgele hareket meydana gelmektedir.

- Parlaklık uygunluk (amaç) fonksiyonu ile belirlenir. En parlak olanı en iyi olarak kabul eden bir uygunluk fonksiyonu vardır.

Ters kare yasasına göre bir ışık kaynağından $\left(l_{s}\right)$ [28], $r$ uzaklıkta elde edilen 1şık şiddeti, $(I(r))$ [29] Eş. 1 ile hesaplanır [30].
$I(r)=l_{s} / r^{2}$

Bir ortamda 1şık yayılırken, 1şık şiddeti belli bir miktar emilime uğrar. Bu yüzden sabit bir 1şık emilim katsayısı $(\gamma)$ dikkate alındığında Eş. 2 elde edilmiş olmaktadır. $I_{0}, r=0$ olduğundaki 1şık kaynağının şiddetidir. Sıfır sayısına bölünmede Eş. 1'in tanımsız durumunda olmaması [13] için mesafe yaklaşı gauss dağılımı şeklinde yazılabilir [31].

$I(r)=I_{0} e^{-\gamma r^{2}}$

Böylece ateşböceğinin çekiciliği Eş. 3 ile hesaplanmaktadır. Çekicilik, aradaki mesafeye bağlı olarak değişmektedir. $B_{0}$ bir ateşböceğinin diğer komşu ateşböceğine aradaki mesafe $r=0$ olduğundaki çekicilik miktarıdır. $B(r)$ ise $B_{0}$ çekiciliğe sahip ateşböceğinin $r$ mesafedeki çekicilik miktarıdır [32].

$B(r)=B_{0} e^{-\gamma r^{2}}$

$i$ ve $j$ iki ateşböceği ve iki boyutlu düzlemde sırasıyla konumları $X_{i}\left(x_{i}, y_{i}\right)$ ve $X_{j}\left(x_{j}, y_{j}\right)$ olsun. Aralarındaki mesafe $\left(r_{i j}\right)$ Öklid bağıntısı yani Eş. 4 vasıtasıyla hesaplanmaktadır.

$r_{i j}=\left\|X_{i}-X_{j}\right\|=\sqrt{\left(x_{i}-x_{j}\right)^{2}-\left(y_{i}-y_{j}\right)^{2}}$

Böylece daha çekici ve parlak $(j)$ olana doğru yönelmiş bir ateşböceğinin (i) yeni konumu $\left(X_{i}\right)$ Eş. 5'teki gibi hesaplanmaktadır [24].

$X_{i}=X_{i}+B_{0} e^{-\gamma r_{i j}^{2}}\left(X_{j}-X_{i}\right)+a\left(\operatorname{rand}-\frac{1}{2}\right)$

Eşitlikteki, $\alpha \in[0,1]$ aralığında sabit bir değer alan katsayı parametresidir [24]. rand ise [0,1] arasında rastgele bir değer almaktadır [33]. $B_{0}$ ise temel cazibe katsayısı olup genellikle $B_{0}=1$ olarak değer almaktadır [34].

\section{4. ÖNERILEN ATEŞBÖCEĞİ ALGORITMASI DEĞİŞIKLİĞI VE İYİLEŞTİRMESİ (PROPOSED MODIFIED AND ENHANCED FIREFLY ALGORITHM)}

Eş. 5' deki gamma ( $(y)$ ortam 1şık emilim katsayısı çok önemli bir göreve sahiptir. Bu katsayı ateşböceği algoritmasının yakınsama hızı ve tavrı ile ilgili önemli bir görevde belirleyici bir rol üstlenmektedir. Teorik olarak $\gamma \in[0, \infty)$ aralığında bir sayı değeri alabilir. Genellikle önceki çalışmalarda bu katsayı değeri sabit olarak 1 veya $[0,10]$ aralığında sabit bir sayı değeri alınarak kullanılmış [27] ve bu aralıkta değer alınarak kullanılması tavsiye edilmiştir [31]. Fakat 1şığın içinde yayıldığı ortama ait olan 1şık emilim katsayısının böylesine doğadan esinlenerek oluşturulmuş bir algoritmada sabit bir sayı olarak kullanılması, algoritma başarısı açısından yeterli ve uygun olmadığı düşünülmektedir.

Örneğin 1şığın içinde yayıldığ 1 ortam hava olarak kabul edilirse hava ile ilgili sisli, tozlu, açık, temiz, kapalı vb. durumlarında olması gibi özellikler söz konusu 
olabilmektedir. Yani, örneğin sisli veya tozlu bir havada 1şık emilim katsayısının $(\gamma)$ çok büyüdüğü, sonsuz değerine gittiği varsayılırsa $(\gamma \rightarrow \infty)$ Eş. 5'deki konum güncellemenin ikinci kısmı sıfıra yakınsayacağından $\left(e^{-\gamma r 2 i j} \rightarrow 0\right)$, yer değiştirme miktarı eşitliğin üçüncü kısımdan $(\alpha($ rand-1/2)) dolayı rastgele olacaktır. Aksine havanın açık ve temiz olduğu bir durumda ise 1 şı emilim katsayısı $(\gamma), \gamma \rightarrow 0$ olacağı varsayılırsa $B(r) \rightarrow B_{0}$ olacaktır. Böylece aradaki mesafenin önemli olmadığı sabit bir çekicilik söz konusu olacaktır [24]

Eş. 5'deki 1 şı emilim katsayısının $(\mathrm{g})$ anlatılan bu sebeplerden dolayı örneğin hava gibi bir ortamın ani değişkenlik (sisli, yağmurlu, kapalı, açık vb.) gösterebilmesi sebebiyle sabit alınması yerine değişken alınması önerilmektedir. Bu sebeple ateşböceği algoritmasında $1 s ̧ 1 \mathrm{k}$ emilim katsayısının $(\mathrm{y})$ başlangıçta sabit ve önerilen bir sayı değeri ile kullanılmasının yerine her döngüde rastgele $[0,10]$ aralığında bir sayı değeri alarak kullanılması önerilmektedir. Optimizasyon algoritmaları problem türüne göre, yerel minimuma takılma ve erken yakınsama problemleri ile karş1 karşıya kalmaktadırlar. Arama uzayında, küresel optimum noktasinın bulunmadan algoritmanın durma kriteri ile sonuca varması veya arama uzayının yeterli aranmamasından kaynaklı daha iyi bir optimum nokta kaçırılabilmektedir. Önerilen yöntemde, daha iyi bir stokastik modeli temel alan ve doğal rastgeleliği ön plana çıkaran bir arama yapısına dönüştürülen ateşböceği algoritması, arama uzayının daha fazla taranmasına sebebiyet vererek bu anlamda ateşböceklerinin çeşitliliğinin artmasına neden olacağı düşünülmektedir.

Tablo 1'de optimizasyon çalışmalarda sıklıkla kullanılan ackley, rosenbrock, sphere kiyaslama problemleri ve bu problemlerin çözümünde kullanılan değişkenlerin aldığ değer aralıkları gösterilmektedir. Tablo 1'de 25 adet birbirinden bağımsız çalıştırma sonucu elde edilen optimizasyon sonuç değerlerinin ortalaması ve standart sapması alınarak gösterilmiştir. Tablodaki daha düşük değerli optimizasyon sonuç ortalaması daha başarılı algoritma anlamına gelmektedir. Buna göre kıyaslama yapılan 3 fonksiyonda da önerilen rastgele 1 şık soğurma katsayılı değiştirilmiş ateşböceği optimizasyon algoritmasının daha başarılı olduğu görülmektedir.

\section{5. ÖNERİLEN ÇOKLU SINIFLAMA YAPAN KURAL TABANLI SINIFLAYICI YAKLAŞIM (PROPOSED RULE-BASED MULTI-CLASS CLASSIFIER APPROACH)}

Optimizasyon süreci, arama uzayında en uygun çözümün aranması ve bulunması şeklinde tanımlanabilir. Makine öğrenmesi sınıflama süreci birçok çalışma alanında başarılı bir şekilde uygulanmaktadır. Son yıllarda yapılan bazı sınıflama ve iyileştirilmesi ile ilgili örnek çalışmalar: uzman karışımlarla elde edilen, karar ağaçları ve $\mathrm{k}$ en yakın komşuluk algoritmasına göre daha başarılı sınıflama yöntemi [35], konuşmacının yaş ve cinsiyetini belirlemek için iyileştirilmiş destek vektör makineleri [36], centroid sınıflayıcı ile meme kanseri teşhisi [37] şeklinde verilebilir. Önerilen kural tabanlı sınıflayıcı yaklaşımında eğitim kümesi içinde her bir sınıf etiketini en iyi şekilde tanımlayan sınıflama kuralını bulabilmek amacıyla optimizasyon kullanılmaktadır. Böylece her bir sınıf etiketi için bulunmuş kurallar ile kural listesi oluşturularak, sınıflayıcı model meydana gelmektedir. Elde edilen bu kurallar genelleştirilmiş ilginç [38], doğru ve anlaşı1ır [39] bir yapıda olabilmektedir. Şekil 1'de önerilen yöntemin akış şemas1 görülmektedir. Buna göre; ilk başta sınıflama modeli oluşturabilmek ve oluşturulan modelin başarısını sınamak için eğitim ve test veri kümeleri sırasıyla $\% 70$ ve $\% 30$ oranları şeklinde ayrılmaktadır. Oluşturulan eğitim kümesinin kayıt yapısı ikili sayı sistemi ile tasarlanmaktadır.

Değiştirilmiş ateşböceği algoritması, her bir sınıf etiket değeri için en iyi kural araması yapar. İlgili sınıf etiketine karşı en geçerli kuralı belirleyebilmek için optimizasyon algoritması tarafindan kullanılan uygunluk fonksiyonu literatürde sık olarak kullanılan başarı ölçütlerinden olan anma, özgüllük, kural karmaşıklık ve kural kapsama ölçütlerinin birleşimi şeklinde oluşturulmuştur [19]. Böylece ilgili sınıf etiket değerini en iyi şekilde tanımlayan en güçlü kural elde edilmiş olmaktadır. Her bir sınıf etiketi için elde edilmiş kurallar ile kural listesi oluşturulmakta ve test veri kümesi örnekleri sınıflanmaktadır. Sınıflama yapılamayan kayıtlar için, eğitim veri kümesinde en fazla kaydı içeren sinıf etiketli bir kural listeye eklenebilir.

Şekil 1'deki önerilen yöntemde eğitim veri kümesine ait özelliklerin ikili sayı sisteminde tasarlanması ve biraraya getirilmesi ile ateşböceği algoritmasının bir bireyi oluşturulmaktadır [19]. Tablo 2'de örnek olarak hastaların kullanması gereken kontak lens tipini belirleyen "lenses" veri kümesine ait 4 adet özellik değeri ve bu özelliklerin alabileceği değerlerin ikili sayı sistemindeki karş1lıkları gösterilmektedir. 1. özellik kategorik olarak 3 farklı değer alabiliyor ise bu durumda her bir kategorik değer için farklı ikili sayı değeri kullanılmaktadır. Örneğin, veri kümesinin 1. özelliği "age of the patient" göz önüne alındığında "young" değeri ikili tabanda 100, benzer şekilde "pre-presbyopic" değeri ikili tabanda 010, "presbyopic" ise ikili tabanda 001 değer karşılığı ile kullanılmaktadır. $\mathrm{Bu}$ şekilde optimizasyonda kullanılacak her bir değişkenin alt sınır ve üst sınırları da belirlenmiş olmaktadır. Örneğin 1.özellik için alt sınır 1, üst sınır ise 4 olmaktadır.

Tablo 1. Optimizasyon fonksiyonları karşılaştırılması (Comparison of optimization functions)

\begin{tabular}{llll}
\hline Fonksiyon & Değişken aralı̆̆ 1 & Klasik ateşböceği ort. & Önerilen ateşböceği ort. \\
\hline Ackley & {$[-32,768,32,768]$} & 9,87 std. 1,82 & 7,38 std. 1,59 \\
Rosenbrock & {$[-5,10]$} & 92631,20 std. 84562,02 & 38114,04 std. 23336,03 \\
Sphere & {$[-5,12,5,12]$} & 28,96 std 10,11 & 14,44 std. 4,13 \\
\hline
\end{tabular}




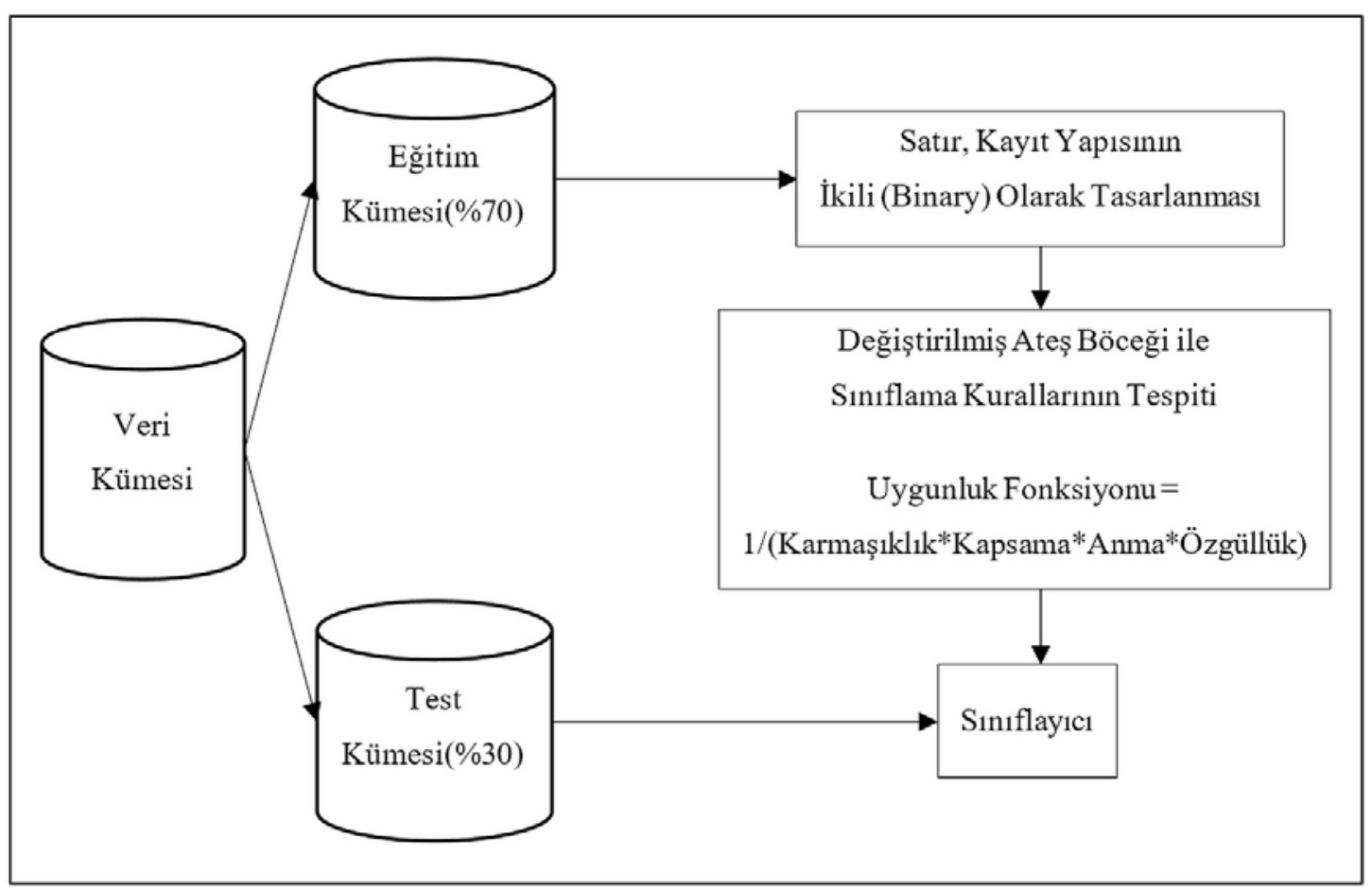

Şekil 1. Önerilen sınıflayıcı yöntemin akış şeması (Flow diagram of proposed method)

Tablo 2. Kayıt yapıs1 (Record structure)

\begin{tabular}{|c|c|c|c|}
\hline Özellik & Ad1 & $\begin{array}{l}\text { Değerler ve ikili } \\
\text { karşıl } \breve{l g}_{1}\end{array}$ & \\
\hline \multirow{3}{*}{ Özellik 1} & \multirow{3}{*}{ age of the patient } & young & 100 \\
\hline & & pre-presbyopic & 010 \\
\hline & & presbyopic & 001 \\
\hline \multirow{2}{*}{ Özellik 2} & spectacle & myope & 10 \\
\hline & prescription & hypermetrope & 01 \\
\hline \multirow{2}{*}{ Özellik 3} & \multirow{2}{*}{ astigmatic } & no & 10 \\
\hline & & yes & 01 \\
\hline \multirow{2}{*}{ Özellik 4} & tear production & \multirow{3}{*}{$\begin{array}{l}\text { reduced } \\
\text { normal } \\
\text { hard } \\
\text { none } \\
\text { soft }\end{array}$} & \multirow{3}{*}{$\begin{array}{l}10 \\
01\end{array}$} \\
\hline & rate & & \\
\hline Sinif & $\begin{array}{l}3 \text { farklı sinıf } \\
\text { etiketi }\end{array}$ & & \\
\hline
\end{tabular}

Tablo 3'de, örneğin, "hard" sınıf etiketine karşılık gelen kural yapısı, veri kümesindeki bütün özellik değerlerinin ikili sayı kodlama karşıllklarının yan yana gelmesi sonucunda oluşmaktadır. Algoritmada her bir özellik ayrı bir değişken olarak alınmaktadır. 4 özellikli bir veri kümesi yapısı için optimizasyon algoritmasının değişken boyutu 4 olmaktadır. "hard" sınıfına ait kural bulunmak istendiği zaman "hard" sinıf etiketi uygunluk fonksiyonunda sabit kalmak üzere arama yapılmaktadır. Optimizasyon algoritmasının çalıştırılması sonucu "hard" sınıfı için elde edilen en iyi çözüm Tablo 3'de gösterildiği gibi olsun. Buna göre örneğin hard sınıfi için kural cümlesi "if age of patient=young and spectacle prescription=myope and astigmatic $=$ no and tear production rate $=$ reduced then sınıf=hard" şeklinde olmaktadır. Bu yapıda dikkat edilmesi gereken durum; eğer bir özellik, Tablo 2'de bulunmayan bir ikili sayı değerini alması durumunda ilgili özelliğin kural cümlesinden çıkarılması gerektiğidir. Örneğin, optimizasyon sonucu aday birey ateşböceği yapısı 2.özellik ve 4.özellik için sırasıyla 00 veya 11 değerini almış ise o halde kural cümlesi "if age of patient=young and astigmatic= no then sınıf=hard" şeklinde olacaktır. "Spectacle prescription" ve "tear production rate" özellikleri bu şekilde karşılığ1 olmayan değerler ile ilgili kuralda yer almayacaktır.

Tablo 3. Kural gösterimi (Rule representation)

\begin{tabular}{lllll}
\hline Özellik & Özellik & Özellik & Özellik & $\begin{array}{l}\text { Sinıf } \\
1\end{array}$ \\
2 & 3 & 4 & özelliği \\
\hline 100 & 10 & 10 & 10 & hard \\
\hline
\end{tabular}

\subsection{Uygunluk (amaç) fonksiyonu (Fitness (objective) function)}

Her bir sınıf değeri için ayrı ayrı en iyi kuralı bulabilmek için literatürde sık kullanılan anma, özgüllük, kural karmaşıklık, kural kapsama gibi ölçütler kullanılmaktadır. Karışıklık matrisi sınıflama başarısının ölçümünde yararlanılan bir tablodur. Tablo 4'de iki sınıf etiketi sahip bir veri kümesi için karışıklık matrisi gösterilmiştir.

Tablo 4. Karışıklık matrisi (Confusion matrix)

\begin{tabular}{llll}
\hline \multirow{2}{*}{ Karışıklık matrisi } & & \multicolumn{2}{c}{ Tahmin sınıfı } \\
& & Sınıf 1 & Sınıf 2 \\
\hline \multirow{2}{*}{ Gerçek sınıf } & Sinıf 1 & TP & FN \\
& Sinıf 2 & FP & TN \\
\hline
\end{tabular}

Bu matriste [23]: True Positive (TP) değeri: Kuralın uygulanması sonucu tahmin sinıf değeri evet (Positive) ve 
gerçekte ilgili kayıt sınıfının evet (Positive) olduğu toplam kayıt sayısını göstermektedir. False Positive (FP) değeri: Kuralın uygulanması sonucu tahmin sinıf değeri evet (Positive) ve gerçekte ilgili kayıt sınıfının hayır (Negative) olduğu toplam kayıt sayısını göstermektedir. True Negative (TN) değeri: Kuralın uygulanması sonucu tahmin sınıf değeri hayır (Negative) ve gerçekte ilgili kayıt sınıfının hayır (Negative) olduğu toplam kayıt sayısını göstermektedir. False Negative (FN) değeri: Kuralın uygulanması sonucu tahmin sınıf değeri hayır (Negative) ve gerçekte de ilgili kayıt sınıfının evet (Positive) olduğu toplam kayıt sayısını göstermektedir. Tablo 4'deki karışıklık matrisinin ölçüt değerleri ile elde edilen;

Kural Kapsama Ölçütü (A): Eş. 6'da gösterildiği gibi hesaplanır. Bir kuralın uygulanması sonucu kuralın "if" kısmı ile kapsanan toplam kayıt sayısının (TP+FP), TP'ye oranı şeklindedir [21].

$$
\text { Kural Kapsama Ölçütü (A) = TP / TP + FP }
$$

Kural Karmaşıklık Ölçütü (C): Eş. 7'de gösterildiği gibi hesaplanır. Bir kuralın “if” kısmında bulunan özellik sayısı ölçütüdür. Eşitlikteki L sayısı bir kuralda en fazla olabilecek özellik sayısı yani veri kümesinin özellik sayısını, $\mathrm{x}$ ise ilgili kuraldaki olan özellik sayısıdır [22].

Kural Karmaşıklık Ölçütü $(\mathrm{C})=\mathrm{L}-\mathrm{x} / \mathrm{L}-1$

Eş. 8 ve Eş. 9'da sirasıyla anma ve özgüllük [16] ölçüt değerleri verilmiştir [17].

$$
\begin{aligned}
& \text { Anma }=\text { TP / (TP + FN }) \\
& \text { Özgüllük = TN / (TN + FP })
\end{aligned}
$$

Eş. 10'da sınıflama kural skorunu belirlemek için değiştirilmiş ateşböceği optimizasyon algoritmasında kullanılacak uygunluk (amaç) fonksiyonu oluşturulmuştur. Uygunluk fonksiyonu sonucunda elde edilen daha küçük değerli bir kural skoru daha başarılı kabul edilmektedir. Ateşböceği optimizasyon algoritması en küçük uygunluk değerli kuralı bulmayı hedeflemektedir. Bu şekilde, önceki bahsedilen ölçütler ile esnek ve hibrit bir uygunluk fonksiyonu oluşturulmuş ve yeterince başarılı sınıflama kural listeleri elde edilmiştir.

Uygunluk (Amaç) fonksiyonu =

1 / (A x C x Anma x Özgüllük)

\section{SONUÇLAR VE TARTIŞMALAR (RESULTS AND DISCUSSIONS)}

Yapılan çalışmalarda literatürde sıklıkla kullanılan ve Tablo 5'de gösterilen üç adet UCI makine öğrenmesi veri tabanından alınmış veri kümesi [40] kullanılmıştır. Kural çıkarım yaklaşımı için veri kümelerinin sayısal özelliklerine ayrıklaştırma ön işlemi uygulanmış ve kategorik hale getirilmiştir. Çalışmalar, Intel Core i7-4770HQ @ 2.20GHz işlemci, 16,0 GB bellek ve Windows10 işletim sistemine sahip bir bilgisayarda, Weka ve Matlab2017a yazılımları kullanılarak yapılmıştır. Elde edilen sonuçlarda, ateşböceği optimizasyon algoritmasının popülasyon büyüklüğü 200 ve döngü sayısı 100 olarak kullanılmıştır.

Iris veri kümesinin "sınıf 1" değeri olan "Iris Setosa" için en yüksek skorlu kural bulunmaya çalışılmıştır. Bu amaçla 4 değişken içeren ve değişkenleri onlu sayı sisteminde [0, 4] aralığında tam sayı olan başlangıç birey yapısı ile ateşböceği optimizasyon algoritması çalıştırılmıştır. 4 değişken olmasının sebebi iris veri kümesinin 4 özelliğinin olması ve bu özelliklerinin Tablo 2'de gösterildiği gibi kayıt yapısının ikili sayı sisteminde alabileceği en az ve en fazla sayı değerlerine göre aralıklarının belirlenmesi sonucu oluşmuştur.

Tablo 6'ya göre iris veri kümesi için kullanılan eğitim kümesi boyutu 105'dir. Toplam 105 kaydın, 100'ü elde edilen kurallar ile doğru bir şekilde sınıflanmıştır. 5 adet kayıt ise elde edilen kurallar ile yanlış sınıflanmıştır. Ateşböceği algoritması iris eğitim veri kümesi için 100/105'den yaklaşık \%95 oranında başarılı olmuştur.

Tablo 7'de car veri kümesi için elde edilen sonuç değerlerine bakıldığında toplam 1209 eğitim verisinden, kuralların "if" kısımları ile 1030 adedi kapsanabilmiştir. Kapsanan 1030 veri içerisinde 604 tanesi başarılı şekilde tahmin edilmiştir. Böylece yaklaşık \%59 oranında bir başarı yüzdesi elde

Tablo 5. Kullanılan veri kümeleri (Used datesets)

\begin{tabular}{|c|c|c|c|c|c|}
\hline Sinif no & Sinif ad1 & En iyi kural & Kapsama & $\mathrm{TP}$ & FP \\
\hline 1 & Iris Setosa & IF petal length $=(-$ inf $-2,45]$ THEN Iris Setosa & 36 & 36 & 0 \\
\hline 2 & $\begin{array}{l}\text { Iris } \\
\text { Versicolour }\end{array}$ & IF petal width $=(0,8-1,75]$ THEN Iris Versicolour & 37 & 33 & 4 \\
\hline 3 & Iris Virginica & IF petal width $=(1,75$-inf $)$ THEN Iris Virginica & 32 & 31 & 1 \\
\hline
\end{tabular}

\begin{tabular}{llll}
\hline Veri kümesi & Kayıt sayıs1 & Özellik sayıs1 & Sinıf sayıs1 \\
\hline Iris & 150 & 4 & 3 \\
Car & 1728 & 6 & 4 \\
Zoo & 101 & 17 & 7 \\
\hline
\end{tabular}

Tablo 6. Iris için elde edilen kurallar (Obtained rules for Iris) 
Tablo 7. Car için elde edilen kurallar (Obtained rules for Car)

\begin{tabular}{llllll}
\hline Sinif no & Sinıf adi & En iyi kural & Kapsama & TP & FP \\
\hline 1 & acc & IF Safety=high THEN acc & 413 & 154 & 259 \\
2 & good & IF Buying=low AND Maint=med THEN good & 78 & 18 & 60 \\
3 & unacc & IF Safety=low THEN unacc & 402 & 402 & 0 \\
4 & vgood & IF Lug_boot=big AND Safety=high THEN vgood & 137 & 30 & 107 \\
\hline
\end{tabular}

Tablo 8. Zoo için elde edilen kurallar (Obtained rules for Zoo)

\begin{tabular}{|c|c|c|c|c|c|}
\hline Sinif no & Sinıf adı & En iyi kural & Kapsama & $\mathrm{TP}$ & $\mathrm{FP}$ \\
\hline 1 & amphibian & $\begin{array}{l}\text { IF eggs =true AND aquatic=true AND toothed=true } \\
\text { AND breathes=true THEN amphibian }\end{array}$ & 4 & 4 & 0 \\
\hline 2 & bird & IF feathers $=$ true THEN bird & 13 & 13 & 0 \\
\hline 3 & fish & IF fins $=$ true AND breathes $=$ false THEN fish & 8 & 8 & 0 \\
\hline 4 & insect & $\begin{array}{l}\text { IF aquatic }=\text { false AND legs }=(4-i n f) \text { AND tail }=\text { false } \\
\text { THEN insect }\end{array}$ & 7 & 7 & 0 \\
\hline 5 & invertebrate & $\begin{array}{l}\text { IF airborne }=\text { false AND predator }=\text { true AND } \\
\text { backbone }=\text { false THEN invertebrate }\end{array}$ & 4 & 4 & 0 \\
\hline 6 & mammal & IF milk=true THEN mammal & 29 & 29 & 0 \\
\hline 7 & reptile & $\begin{array}{l}\text { IF feathers }=\text { false } \text { AND eggs }=\text { true } \text { AND } \\
\text { aquatic }=\text { false AND tail }=\text { true THEN reptile }\end{array}$ & 4 & 4 & 0 \\
\hline
\end{tabular}

edilmiştir. Car veri kümesinde bulunan özellikler daha fazla kategorik değerler içermektedir. Bu veri kümesinde her bir sinıfi tanımlayan en iyi tek bir kural yerine optimizasyon sonucu elde edilen ilgili sinıfa ait kurallar listesinden daha fazla kural siniflama listesine eklenebilir. $\mathrm{Bu}$ sebeple özelliklere ait kategorik değerlerin fazla olduğu bu gibi bir veri kümesi için her bir sınıfı tanımlayan tek bir kuralın yeterli gelmediği görülmüştür.

Zoo veri kümesi için yapılan çalışmada, hatalı tahmin oranın olmadığ 1 görülmektedir. Her bir sınıf kural tarafından iyi derecede sınıflandırılmıştır. Tablo 8'de, 71 adet eğitim verisinin 69 adedi başarılı şekilde kapsanmış ve doğru şekilde sınıflandırılmıștır. Böylece başarı \%100 olarak hesaplanmıştır. Sonraki deneysel çalışmada ise, eğitim veri seti ile oluşturulmuş kural tabanlı sınıflayıcı modele, başlangıçta test verisi olarak ayrılmış test verileri uygulanmıştır. Test verileri, ateşböceği algoritması ile elde edilen sınıflama kuralları ile oluşturulmuş sınıflayıcı modele uygulandığında elde edilen sonuçlar Şekil 2'deki gibidir. Elde edilen kural listesi ile siniflanamayan geri kalan kayıtlara, veri kümesinin en baskın sınıfına ait etiket verilmiştir. Buna göre eğitim veri setinde elde edilen sonuçların test veri seti sonuçlarına da yansıdı ğ görülmektedir. Şekil 2'de iris, zoo ve car veri kümeleri için doğruluk, kesinlik ve F-ölçümü gibi sınıflama başarı ölçütleri üzerinden bakıldığında yüksek değerlerin elde edildiği görülmektedir. Bunun yanı sıra, car veri kümesine ait sınıflama başarı değerleri düşük kalmaktadır. Bu durum, bu veri kümesinin daha karmaşık olmasından yani diğer veri kümelerine göre özellik değerlerinin daha fazla sayıda kategorik değerlere sahip olmasından kaynaklandığ 1 düşünülmektedir. Bir sonraki deneysel çalışmada, önerilen kural tabanlı ateşböceği sınıflama algoritması, diğer başarılı bazı sınıflama algoritmaları ile karşılaştırılmıştır. Önerilen yöntemin, tutarlı ve iyi sonuçlar verdiği Şekil 3'de gösterilmektedir. Naive-Bayes algoritması olasılık temelli bir sınıflama yöntemidir. C4.5 karar ağaçları, bilgi kazanç hesaplamasinı temel alan bir sinıflama algoritmasidır. PART algoritması ise literatürde kural tabanlı sinıflayıcı bir algoritma olarak geçmektedir. Önerilen yöntemin, zoo veri kümesinde diğerlerine göre daha iyi olduğu, iris veri kümesinde tutarlı sonuçlar verdiği görülmektedir. Car veri kümesi için ise diğer yöntemlere göre daha düşük doğruluk değeri elde edildiği görülmektedir. Bunun başlıca sebebi, car veri kümesini daha başarılı sınıflayabilmek için her sınıf etiketine ait tek bir sınıflama kuralının yetersiz olmasından kaynaklanmaktadır. $\mathrm{Bu}$ yüzden, ileride yapılacak çalışmalarda ateşböceği algoritması sonuç havuzundan bir sınıfa ait birden fazla sayıda kural alınarak ilgili sınıfa ait daha büyük kural listesinin oluşturulması sağlanabilir. Ayrıca başlangıç aday birey kural yapısı tek bir kural içermek yerine birbirinden farklı birden fazla kural içerecek şekilde yeniden tasarlanabilir.

Yapılan deneysel çalışmalarda elde edilen sonuçlara bakıldığında diğer iris, zoo veri kümeleri için her bir sınıfa ait en iyi tek bir kuralın sınıflama başarısı açısından yeterli olduğu görülmektedir. Kural çıkarımı algoritmasında kural yapısında sadece eşittir $(=)$ kullanımının yanı sıra büyüktür $(>)$ veya küçük eşittir (<=) gibi kıyaslama operatörlerinin eklenmesi sürekli değer alan niteliklerin kategorik değerlere dönüşümü gibi fazla iş yükünü azaltacağı gibi bunun yanı sıra daha hassas bir kapsama ve True Positive (TP) başarı oranı sağlayabilir. Tablo 9'da, $m$ adet nitelik içeren örnek bir veri kümesi için bir ateşböceği başlangıç birey kural yapısı 


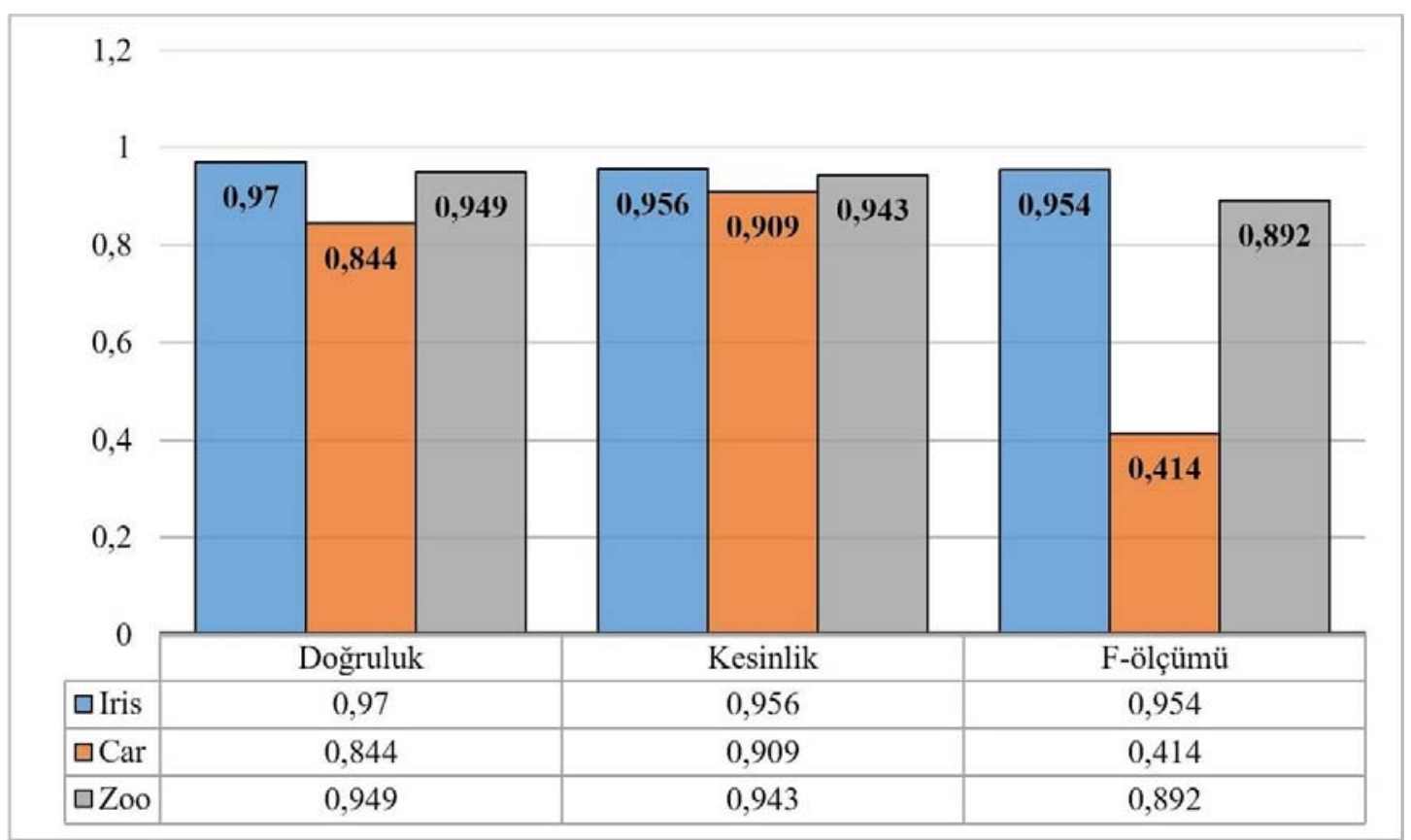

Şekil 2. Önerilen sınıflayıcı yöntemin ile test verisi değerlendirmesi (Evaluation of proposed classifier method with test data)

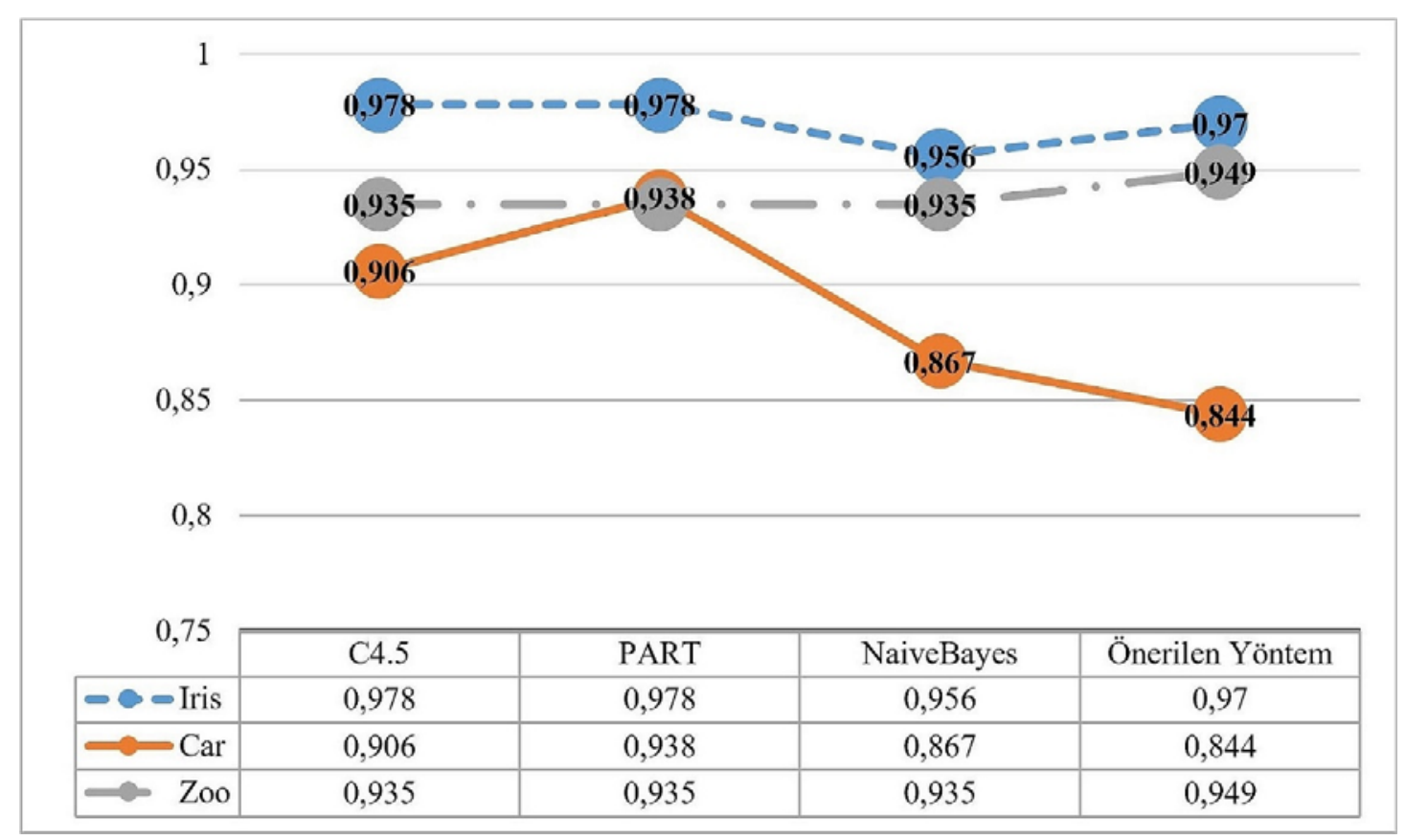

Şekil 3. Önerilen yöntem ve diğer yöntemlerin doğruluk karşılaştırılması (Accuracy comparision of proposed method and other methods)

gösterilmektedir. Bu yap1 ile örneğin, özellik 1'e ait olan operatör (Op1) değeri, eğer özellik 1 kategorik ise eşittir $(=)$, sürekli ise küçük eşittir $(<=)$ veya büyüktür $(>)$ şeklindeki bir kıyaslama operatör değeri alabilir. Tablodaki değer (Değ1) alanı ise ilgili niteliğin alabileceği kategorik veya sürekli değeri ifade etmektedir $[15,36]$. Bu amaçla ileride yapılacak çalışmalara, ateşböceği başlangıç aday birey kural yapısı içine, ikili sayı sistemi kullanılarak farklı kıyaslama operatörleri ile değişik başlangıç kural yapısı tasarımları yapılabileceği önerilebilir.

Tablo 9. Ateşböceği birey kural yapısı (Firefly individual rule structure)

\begin{tabular}{|c|c|c|c|}
\hline Özellik 1 & Özellik 2 & Özellik... & Özellik $m$ \\
\hline Değ 1 & Değ2 & Op... & Değm \\
\hline
\end{tabular}


Tablo 10. Büyük boyutlu Arrhythmia veri kümesi (High dimensional Arrhythmia dataset)

\begin{tabular}{lllllllll}
\hline \multirow{2}{*}{ Sinıf } & \multicolumn{1}{c}{ Önerilen Ateşböceği A. } & \multicolumn{5}{c}{ Standart Ateşböceği A. } \\
\cline { 2 - 9 } & Kapsama & TP & FP & $\%$ & Kapsama & TP & FP & $\%$ \\
\hline 1 & 163 & 108 & 55 & 0,66 & 231 & 146 & 85 & 0,63 \\
2 & 40 & 7 & 33 & 0,18 & 21 & 1 & 20 & 0,05 \\
3 & 1 & 1 & 0 & 1,00 & 24 & 1 & 23 & 0,04 \\
4 & 14 & 1 & 13 & 0,07 & 0 & 0 & 0 & Yok \\
5 & 3 & 3 & 0 & 1,00 & 2 & 2 & 0 & 1,00 \\
6 & 14 & 9 & 5 & 0,64 & 4 & 3 & 1 & 0,75 \\
7 & 1 & 1 & 0 & 1,00 & 298 & 4 & 294 & 0,01 \\
8 & 2 & 1 & 1 & 0,50 & 142 & 2 & 140 & 0,01 \\
9 & 2 & 2 & 0 & 1,00 & 2 & 1 & 1 & 0,50 \\
10 & 56 & 11 & 45 & 0,20 & 0 & 0 & 0 & Yok \\
11 & 41 & 13 & 28 & 0,32 & 0 & 0 & 0 & Yok \\
12 & 3 & 2 & 1 & 0,67 & 57 & 5 & 52 & 0,09 \\
13 & 2 & 2 & 0 & 1,00 & 1 & 1 & 0 & 1,00 \\
Top. & 342 & 161 & 181 & 0,47 & 782 & 166 & 616 & 0,21 \\
\hline
\end{tabular}

Önerilen değiştirilmiş ateşböceği ile standart ateşböceği algoritmalarının sınıflama başarısı üzerindeki farkının, nitelik sayının düşük ve kategorik değerlerinin az olduğu veri kümelerinde daha sınırlı olduğu görülmüştür. Bu farkın daha net görülmesi amaciyla büyük boyutlu Arrhythmia veri kümesi kullanılmıştır. Arrhythmia veri kümesi 262 adet niteliğe ve 13 adet sınıfa sahip olup, toplam 452 kayıttan oluşmaktadır. Tablo 10'a göre, 13 adet sınıfin 10'nunda önerilen algoritmanın, standart algoritmaya göre daha başarılı olduğu, 2 tanesinde eşit ve sadece 6.sınıfta kapsama ve TP değerlerinin önerilen algoritmada daha iyi olmasına rağmen daha kötü performans sergilediği görülmektedir. Önerilen yöntem ile tüm sınıflara ait sınıflama kuralları bulunmuş iken, standart algoritma ile 4, 10 ve 11 numaralı sınıflara ait herhangi bir kural bulunamamıştır. Genel sınıflama başarısı önerilen yöntem için \%47 iken bu oranın standart algoritmada \%21'de kaldığı görülmektedir.

\section{SONUÇLAR (CONCLUSIONS)}

İyileştirilmiş ateşböceği algoritması ile kural tabanlı çok sınıflı veri kümelerinde sınıflama yapabilen yeni bir sınıflayıcı model yaklaşımı ortaya konulmuştur. Önerilen değiştirilmiş ateşböceği optimizasyon algoritması mevcut standart ateşböceği algoritmasına göre daha başarılı sonuçlar vermektedir. Bunun sebebi, doğadan esinlenerek oluşturulmuş temel algoritmadaki ateşböceklerinin bulunduğu ortamda (örneğin hava vb.) meydana gelebilecek değişiklikleri göz önüne alan, değişken ışık emilim katsayısı kullanılmasının önerilmesinden kaynaklanmaktadır. Örneğin havanın sisli olma durumunun 1şık geçirgenliği üzerinde etkileri vardır. Dolayısıyla anlık bu gibi rastgele oluşabilecek değişimlere karşı 1 şık emilim katsayısının da rastgele değerler alması optimizasyon kıyaslama ackley, rosenbrock ve sphere fonksiyonlarında ve Arrhythmia veri kümesinde daha iyi sonuçlar elde edilmesini sağlamıştır. Geliştirilmiş yeni ateşböceği algoritması ile iris, car ve zoo veri kümelerinden sinıflama kuralları elde edilerek, sınıflama kural listesi oluşturulmuştur. $\mathrm{Bu}$ oluşturulan sınıflama kural listesi ile yeni bir sinıflayıcı model elde edilmiştir. Veri kümelerine ait test verileri ile başarılı doğruluk, kesinlik ve F-ölçümü sınıflama değerlendirme ölçüt değerleri elde edilmiştir. Önerilen yöntemin diğer sınıflama yöntemleri C4.5, PART ve Naive-Bayes ile kıyaslanması sonucu, önerilen yöntem ile elde edilmiş sonuçların yeterince iyi ve tutarlı olduğu görülmüştür.

\section{KAYNAKLAR (REFERENCES)}

1. Okay F.Y., Ozdemir S., Improving Coverage in Wireless Sensor Networks Using Multi-Objective Evolutionary Algorithms, Journal of the Faculty of Engineering and Architecture of Gazi University, 30 (2), 143-53, 2015.

2. Demir Y., Celik C., An Integer Programming Approach for Curriculum Based Timetabling Problem Solution, Journal of the Faculty of Engineering and Architecture of Gazi University, 31 (1), 145-59, 2016.

3. Zhonga F., Lia H., Zhongb S., A modified ABC algorithm based on improved-global-best-guided approach and adaptive-limit strategy for global optimization, Applied Soft Computing, 46, 469-486, 2016.

4. Cuicui Y., , Junzhong J., Jiming L., Baocai Y., Bacterial foraging optimization using novel chemotaxis and conjugation strategies, Information Sciences, 363, 7295, 2016.

5. Emary E., Zawba H.M., Hassanien A.E., Binary grey wolf optimization approaches for feature selection, Neurocomputing, 172, 371-81, 2016.

6. Wang H., Wang W.J., Sun H., Rahnamayan S., Firefly algorithm with random attraction. Int J Bio-Inspir Com., 8 (1), 33-41, 2016.

7. Verma O.P., Aggarwal D., Patodi T., Opposition and dimensional based modified firefly algorithm, Expert Syst Appl., 44, 168-76, 2016.

8. Nekooeimehr I., Lai-Yuen S.K., Adaptive semiunsupervised weighted oversampling (A-SUWO) for imbalanced datasets, Expert Syst Appl., 46, 405-16, 2016. 
9. Rudzinski F., A multi-objective genetic optimization of interpretability-oriented fuzzy rule-based classifiers, Appl Soft Comput., 38, 118-33, 2016.

10. Wu J., Yang L., Li T.R., Zhang C.J., Li Z.H., Rule-based fuzzy classifier based on quantum ant optimization algorithm, J Intell Fuzzy Syst., 29 (6), 2365-71, 2015.

11. Lee J.H., Yeh W.C., Chuang M.C., Web page classification based on a simplified swarm optimization, Appl Math Comput., 270, 13-24, 2015.

12. Pourpanah F., Lim C.P., Saleh J.M., A hybrid model of fuzzy ARTMAP and genetic algorithm for data classification and rule extraction, Expert Syst Appl., 49, 74-85, 2016.

13. Wang H., Zhou X., Sun H., Yu X., Zhao J., Zhang H., Cui L., Firefly algorithm with adaptive control parameters, Soft Comput, DOI 10.1007/s00500-0162104-3, 2016.

14. Wang B., Li D.X., Jiang J.P., Liao Y.H., A modified firefly algorithm based on light intensity difference, $\mathrm{J}$ Comb Optim., 31 (3), 1045-60, 2016.

15. Al-Maqaleh, B., Shabazakia, H., A genetic algorithm for discovering classification rules in data mining, International Journal of Computer Applications, 41, 18, 40- 44, 2012.

16. Fidelis M.V., Lopes H.S., Freitas A.A., Discovering comprehensible classification rules with a genetic algorithm, Proc. 2000 Congress Evolutionary Computation, 805-810, 2000.

17. Gundogan K.K., Alatas B., Karci A., Mining classification rules by using genetic algorithms with non-random initial population and uniform operator, Turkish Journal of Electrical Engineering and Computer Sciences (ELEKTRIKK), 12 (1), 43-52, 2004.

18. Bandyopadhyay S., Murthy C.A., Pal S.K., Pattern classification using genetic algorithms, Determination of H. Pattern Recogn Lett., 19 (13), 1171-81, 1998.

19. Sharma P., Discovery of Classification Rules Using Distributed Genetic Algorithm, In: Proceedings of the International Conference on Information and Communication Technologies, ICICT 2014, 2014.

20. Fadl M. Ba-Alwi., Knowledge Acquisition Tool for Classification Rules using Genetic Algorithm Approach, International Journal of Computer Applications, 60, 1, 2012.

21. Pedersen M., Genetic Algorithms for Rule Discovery in Data Mining, Daimi, University of Aarhus, October, 2003.

22. Vivekanandan P., Rajalakshmi M., Nedunchezhian R., An Intelligent Genetic Algorithm for Mining Classification Rules in Large Datasets, Comput Inform., 32 (1), 1-22, 2013.

23. Tan K. C., Tay A., Lee T. H., Heng C. M., Mining multiple comprehensible classification rules using genetic programming, in Proc. 2002 Congr. Evol. Comput., vol. 2, Piscataway, NJ: IEEE, May, 13021307, 2002.

24. Yang X.S., Firefly algorithms for multimodal optimization, Stochastic Algorithms: Foundations and
Appplications, SAGA 2009, Lecture Notes in Computer Science, 5792, Springer-Verlag, Berlin, 169-178, 2009.

25. Pouyan B.M., Yousefi R., Ostadabbas S., Nourani M., A Hybrid Fuzzy-Firefly Approach for Rule-Based Classification, In: The Twenty-Seventh International Flairs Conference, 2014.

26. Sarac, E., Ozel, S.A., Web Page Classification Using Firefly Optimization, In: Innovations in Intelligent Systems and Applications(INISTA), IEEE International Symposium, 1-5, 2013.

27. Pekdemir G., Çoklu İmge Eşikleme Problemlerinde Metasezgisel Algoritmaların Performans Analizi, Selçuk Üniversitesi, Fen Bilimleri Enstitüsü, Bilgisayar Mühendisliği Anabilim Dalı Yüksek Lisans Tezi, 2012.

28. Karaarslan E., Zengin K., Ateş Böceği Algoritması İle Haftalık Ders Programı Hazırlama, EEB 2016 ElektrikElektronik ve Bilgisayar Sempozyumu, Tokat, 11-13 Mayıs, 2016.

29. Belen M.A., Alıcı M., Çor A., Güneş F., Ateşböceği Algoritması ile Mikrodalga Transistör Performans Karakterizasyonu, Eleco 2014 Elektrik - Elektronik Bilgisayar ve Biyomedikal Mühendisliği Sempozyumu, Bursa, 27 - 29 Kasim, 2014.

30. Cheung N.J., Ding X-M, Shen H-B., Adaptive firefly algorithm: parameter analysis and its application. PLoS One 9 (11): e112634. doi:10.1371/journal.pone. 0112634, 2014.

31. Lukasik S., Zak S., Firefly algorithm for continuous constrained optimization task, ICCCI 2009, Lecture Notes in Artificial Intelligence, 5796, 97-100, 2009.

32. Palit S., Sinha S., Molla M., Khanra A., Kule M., A cryptanalytic attack on the knapsack cryptosystem using binary firefly algorithm, in: The Second International Conference on Computer and Communication Technology (ICCCT-2011), IEEE, 428-432, 2011.

33. Crawford B., Soto R., Olivares-Suarez M., Palma W., Paredes F., Olguin E., Norero E., A binary coded firefly algorithm that solves the set covering problem. 17, 252264, 2014.

34. Gümeli D.R., Elektrik Güç Sistemlerinde Sistem Genişlemesi Koşulları Altında İşletmenin Eniyilenmesi İçin Yeni Bir Akıllı Yöntem Geliştirilmesi, İstanbul Teknik Üniversitesi, Fen Bilimleri Enstitüsü, Elektrik Mühendisliği Anabilim Dalı, Doktora Tezi, 2014.

35. Bulut F., Amasyalı M., Classification in Mixture of Experts Using Hard Clustering and a New Gate Function, Journal of the Faculty of Engineering and Architecture of Gazi University, 31 (4), 1017-1025, 2016.

36. Yücesoy E., Nabiyev V., Determination of a Speaker's Age and Gender with an SVM Classifier Based on GMM Supervectors, Journal of the Faculty of Engineering and Architecture of Gazi University, 31 (3), 501-509, 2016.

37. Takc1 H., Diagnosis of Breast Cancer by the Help of Centroid Based Classifiers, Journal of the Faculty of Engineering and Architecture of Gazi University, 31(2), 323-330, 2016. 
38. Alataş B., Özer A., Mining of Generalized Interesting Classification Rules with Artificial Chemical Reaction Optimization Algorithm, Journal of the Faculty of Engineering and Architecture of Gazi University, 32 (1), 101-118, 2017.

39. Akyol S., Alataş B., Automatic Mining of Accurate and Comprehensible Numerical Classification Rules with
Cat Swarm Optimization Algorithm, Journal of the Faculty of Engineering and Architecture of Gazi University, 31 (4), 839-857, 2016.

40. Lichman M., UCI Machine Learning Repository http://archive.ics.uci.edu/ml. Irvine, CA: University of California, School of Information and Computer Science, 2013. 
